\title{
Study of Fluidization Regimes using OpenFOAM Computational Fluid Dynamics
}

\author{
Prasanna Welahettige ${ }^{1}$, Bernt Lie ${ }^{1}$, Knut Vaagsaether ${ }^{1}$, Britt M.E Moldestad ${ }^{1}$ \\ ${ }^{1}$ Department of Process, Energy and Environmental Technology \\ University College of Southeast Norway \\ Porsgrunn, Norway \\ knut. vagsather@usn. no
}

\begin{abstract}
The objective of this study was using computational fluid dynamics simulation with OpenFOAM to study the fluidization properties for four types of particles classified as Geldart A, B, C and D. Fluidization regimes were studied for particles with the same density but different diameters. The particle diameters were selected based on Geldart's classification of particles. The simulation results were validated against experimental data. Pressure gradient, flow regime change, bubble rise, bubble splitting and bed expansion were studied for all four types of particles for different superficial velocities. Group-B and D particles easily produced bubbles. However, Group-C and A particles gave very high bed expansion, and no clear bubbles were observed. Bed with the Group-D particles, the bubbles was large and some of the bubbles reached the diameter of the bed. Group-B particles gave smaller and on average more stable bubbles than Group-D particles. There was no bubble formation from Group-C and Group-A until the inlet superficial velocity was 25 times and 5 times larger, respectively, than their minimum fluidization velocities.

Keywords: Fluidization, bubble, Geldart's classification, pressure gradient, flow regimes, OpenFOAM
\end{abstract}

\section{Introduction}

The gas-solid fluidization process can be divided into two basic steps: the packed bed and the fluidization regime. The packed bed pressure drop can be explained using the Ergun equation up to a minimum fluidization. The pressure drop across the fluidization flow regime can be explained using the mixture momentum balance equation. At the minimum fluidization condition, the buoyant force and the drag force are equal and balance each other in opposite directions (Gidaspow, 1994). According to Geldart's classifications of powder, uniformly sized powders can be classified into four basic types: aeratable (Group-A), bubbling (Group-B), cohesive (Group-C) and spoutable (Group-D), (Geldart, 1972). Group-A particles show considerable bed expansion before the bubbles appear. Group-B particles give bubbles as soon as the gas velocity exceeds the minimum fluidization condition (Kunii \& Levenspiel,
1991). The agglomerate diameter of Group-A particles depends upon a force balance between cohesive, drag, gravity, and collision forces (Motlagh et al., 2014). Group-C particles have difficulties in rising due to the inter particle forces that are stronger than the fluid forces exerted on particles (Gidaspow, 1994). Group-D particles give a slower bubble rise velocity than the gas velocity (Kunii \& Levenspiel, 1991). (Wang X. et al., 2007) showed that Nano-sized particles possess both Group-A and Group-B behavior. Group-B bubbles, which are at the interface between dense phase and freeboard, affect bed collapse time (Pei et al., 2009). (Pandit et al., 2005) found that high bed expansion happens at the particle size boundary between Group-A and B. (Alavi \& Caussat, 2005) found that the fluidization behavior improved for the highest vibration strengths. (Zhang et al., 2008) simulated Group-A and $\mathrm{B}$ particles using a commercial computational fluid dynamics (CFD) tool. There are a number of CFD studies on the gas-solid fluidization. However, few open source CFD studies about all four types of Geldart's groups of particles are published. In this work, all four types of particles were simulated using OpenFOAM 4.0, 2-D simulations. The standard "twoPhaseEulerFoam" model was used for the simulations. All the four particle types were studied with respect to of pressure gradients, flow regime changes, bed expansion, bubble formations and bubble rises.

\section{Numerical models}

The Euler-Euler model was used to simulate both phases. In this approach, the sum of phase volume fractions equals unity and the phase volume fraction is a continuous function of space and time (Rusche, 2002).

$$
\alpha_{g}+\alpha_{s}=1
$$

Here, $\alpha$ is the volume fraction and subscripts $g$ and $s$ indicate gas and solid phases. Continuous phase velocity varies significantly over the volume when the flow becomes turbulent. Therefore, average velocities are introduced in the continuity equation (Crowe et al., 2011)

$$
\frac{\partial \rho_{g} \alpha_{g}}{\partial t}+\nabla \cdot\left(\rho_{g} \bar{U}_{g} \alpha_{g}\right)=0
$$


The $x$ momentum equation for continuous phase can be given as (Rusche, 2002) and (Crowe et al., 2011).

$$
\begin{aligned}
\frac{\partial \rho_{g} \alpha_{g} \bar{u}_{g}}{\partial t}+\nabla & \cdot\left(\alpha_{g} \rho_{g} \bar{u}_{g} \bar{U}_{g}\right) \\
& =-\alpha_{g} \frac{\partial \overline{\mathrm{p}}}{\partial \mathrm{x}}+\nabla \cdot \bar{\tau}_{g, x} \\
& +\alpha_{g} \rho_{g} g_{x}+\overline{\mathrm{M}}_{g, x}
\end{aligned}
$$

Here, $\bar{u}_{g}$ is the $x$ directional velocity of the continuous phase, $\rho_{g}$ is the density of the continuous phase, $\vec{U}_{g}$ is three dimensional velocity components of the continuous phase, $\overline{\mathrm{p}}$ is the pressure, $\bar{\tau}_{g, x}$ is the $x$ component Reynold average stresses, $g_{x}$ is the acceleration of gravity in the $x$ direction, $\overline{\mathrm{M}}_{g, x}$ is the average interface momentum transfer term per unit volume,

$$
\overline{\mathrm{M}}_{g, x}=F_{d}+F_{l}+F_{v m}+F_{o}
$$

Here, $F_{d}$ is the drag force, $F_{l}$ is the lift force, $F_{v m}$ is the virtual force and $F_{o}$ is the other force. Lift force, virtual force and other forces were neglected. The drag force for unit volume is,

$$
\mathrm{F}_{d}=\beta^{\prime}\left(v_{s}-v_{g}\right)
$$

The friction coefficient between fluid and solid $\left(\beta^{\prime}\right)$ (Gidaspow, 1994) depends on $\alpha_{g}$ :

if $\alpha_{g}<0.8$, Ergun's formula applies,

$$
\beta^{\prime}=150 \frac{\alpha_{s}^{2} \mu_{g}}{\alpha_{g}\left(d_{p} \emptyset_{s}\right)^{2}}+1.75 \frac{\rho_{g}\left|v_{g}-v_{s}\right| \alpha_{s}}{\emptyset_{s} d_{p}},
$$

while if $\alpha_{g}>0.8$, Wen and Yu's formula applies,

$$
\beta^{\prime}=\frac{3}{4} C_{D} \frac{\alpha_{g}\left|v_{g}-v_{s}\right| \rho_{g} \alpha_{s}}{d_{p}} \alpha_{g}{ }^{-2.65}
$$

Here, $\mu_{g}$ is the gas viscosity and the drag coefficient $\left(C_{D}\right)$ depends on Reynold's number:

$$
\begin{aligned}
& \text { if } R e_{S}<1000, \\
& C_{D}=\frac{24}{R e_{S}}\left(1+0.15\left(R e_{S}\right)^{0.687}\right),
\end{aligned}
$$

$$
\begin{gathered}
\text { if } R e_{s} \geq 1000, \\
C_{D}=0.44
\end{gathered}
$$

Here,

$$
R e_{S}=\frac{\alpha_{g} \rho_{g}\left|v_{g}-v_{S}\right| d_{p}}{\mu_{g}}
$$

The restitution coefficient, which evaluates the particleparticle collision, was 0.8 . The Johnson-Jackson model calculates friction stress between wall and particles. The minimum fluidization velocity $\left(u_{g, m f}\right)$ is

$$
u_{g, m f}=\frac{d_{p}^{2}\left(\rho_{p}-\rho_{g}\right) g}{150 \mu_{g}} \frac{\alpha_{g, m f}^{3} \phi_{p}^{2}}{\alpha_{s, m f}} .
$$

Here, $d_{p}$ is the particle diameter, $\rho_{p}$ is the density of the particle, $\emptyset_{p}$ is the sphericity of the particle. Maximum bubble size $\left(d_{b, \max }\right)$ according to Mori and Wen (Kunii \& Levenspiel, 1991) is

$$
d_{b, \max }=0.65\left(\frac{\pi}{4} d_{t}^{2}\left(u_{0}-u_{m f}\right)\right)^{0.4} .
$$

Here, $d_{t}$ is the channel width. According to the Grace correlation (Gidaspow, 1994), a single bubble velocity $\left(u_{b r}\right)$,

$$
u_{b r}=0.711 \sqrt{g d_{b}} \text {. }
$$

The velocity of bubbles in a bubbling bed is

$$
u_{b}=u_{0}-u_{m f}+u_{b r} \text {. }
$$

Here, $d_{B}$ is the average bubble diameter and $u_{0}$ is the inlet gas velocity.

2-D simulations were done using the open source CFD code OpenFOAM 4.0. The forward Euler method was used for the time discretization. Pressure-velocity coupling was solved by the pressure implicit with splitting of operators (PISO) algorithm with second order upwind correction.

Grid size (mesh resolution) is a critical factor for the gassolid two fluid method (TFM). Grid size needs to have sufficient scale resolution to accurately predict the bed expansion (Wang J. et al., 2011). When the grid size is smaller than 10 times the particle diameter, a homogenous drag model reached its asymptotic results (Lu et al., 2009). The simulations failed to predict Geldart's A particle when using a fine mesh (Lu et al., 2011) and (Wang J. et al., 2009). Therefore, $7 \mathrm{~mm}$ minimum cell size mesh was used for $1.5 \mathrm{~mm}$ maximum size particle diameter.

\section{Physical properties of gas-solid system}

Table 1 shows physical properties of the particle groups. Particle density and fluid density were constants for the groups. Corresponding particle diameters were selected 
based on Geldart's powder classification diagram (Geldart, 1972).

Table 1. Physical properties of gas-solid system

\begin{tabular}{|l|l|l|l|l|}
\hline \multicolumn{1}{|c|}{ Parameters } & $\begin{array}{c}\text { Group- } \\
\text { A }\end{array}$ & $\begin{array}{c}\text { Group- } \\
\text { B }\end{array}$ & $\begin{array}{c}\text { Group- } \\
\text { C }\end{array}$ & $\begin{array}{c}\text { Group- } \\
\text { D }\end{array}$ \\
\hline $\begin{array}{l}\text { Particle diameter, } d_{p}, \\
(\mu \mathrm{m})\end{array}$ & 60 & 350 & 15 & 1500 \\
\hline $\begin{array}{l}\text { Particle density, } \rho_{s}, \\
\left(\mathrm{~kg} / \mathrm{m}^{3}\right)\end{array}$ & 2500 & 2500 & 2500 & 2500 \\
\hline $\begin{array}{l}\text { Fluid density, } \rho_{g}, \\
\left(\mathrm{~kg} / \mathrm{m}^{3}\right)\end{array}$ & 1.225 & 1.225 & 1.225 & 1.225 \\
\hline $\begin{array}{l}\text { Calculated minimum } \\
\text { fluidization velocity, } \\
u_{g, m f},(\mathrm{~m} / \mathrm{s})\end{array}$ & 0.0035 & 0.15 & 0.00024 & 2.4 \\
\hline
\end{tabular}

\section{Results and discussion}

Results were categorized for each group as a comparison. Pressure gradient across a bed was calculated as an average pressure difference between two points in the bed, which were $30 \mathrm{~mm}$ and $235 \mathrm{~mm}$ vertical height from the bed bottom. The average pressure was calculated as an area average pressure. The channel with was $0.084 \mathrm{~m}$ and channel height was different depending on the expansion of the groups.

\subsection{Group-A}

\subsubsection{Pressure gradient}

The pressure gradient increased proportionally with the inlet superficial velocity until the minimum fluidization velocity was reached. At minimum fluidization, the packed bed gave a maximum pressure gradient as shown in Figure 1. The minimum fluidization velocity was $0.006 \mathrm{~m} / \mathrm{s}$. (Ye et al., 2005)) also observed a similar pressure drop pattern with the inlet superficial velocities for Group-A particles.

\subsubsection{Fluidization regimes}

Figure 3 shows bed expansions with different inlet superficial velocities. There was no considerable bed expansion before the minimum fluidization velocity was reached. However, after the minimum fluidization, the bed expanded considerably. Here, the dense phase was gradually transitioned into the dilute phase. There was no bubble formation until the inlet superficial velocity was five times higher than the minimum fluidization velocity. This bubble less bed expansion behavior was also observed by (Wang X. et al., 2007). However, when the inlet velocity was further increased, the airflow tried to create flow channels in the expanded bed. (Karimipour \& Pugsley, 2010) also observed a similar behavior, when the bed expanded, it gradually compromised into a normal bubbling bed.

\subsection{Group-B}

\subsubsection{Pressure gradient}

Figure 4 shows pressure gradient variation with the inlet superficial velocity. The pressure gradient gradually increased until minimum fluidization occurred, and then it became (on average) constant. The minimum fluidization velocity was $0.16 \mathrm{~m} / \mathrm{s}$ in the experiment and $0.18 \mathrm{~m} / \mathrm{s}$ in the simulation. The average particle diameter was $350 \mu \mathrm{m}$ in the experiment (Thapa \& Halvorsen, 2013). However, in the simulation only $350 \mu \mathrm{m}$ diameter particles was used. This could be the reason for having a little difference between the simulation result and the experimental result.

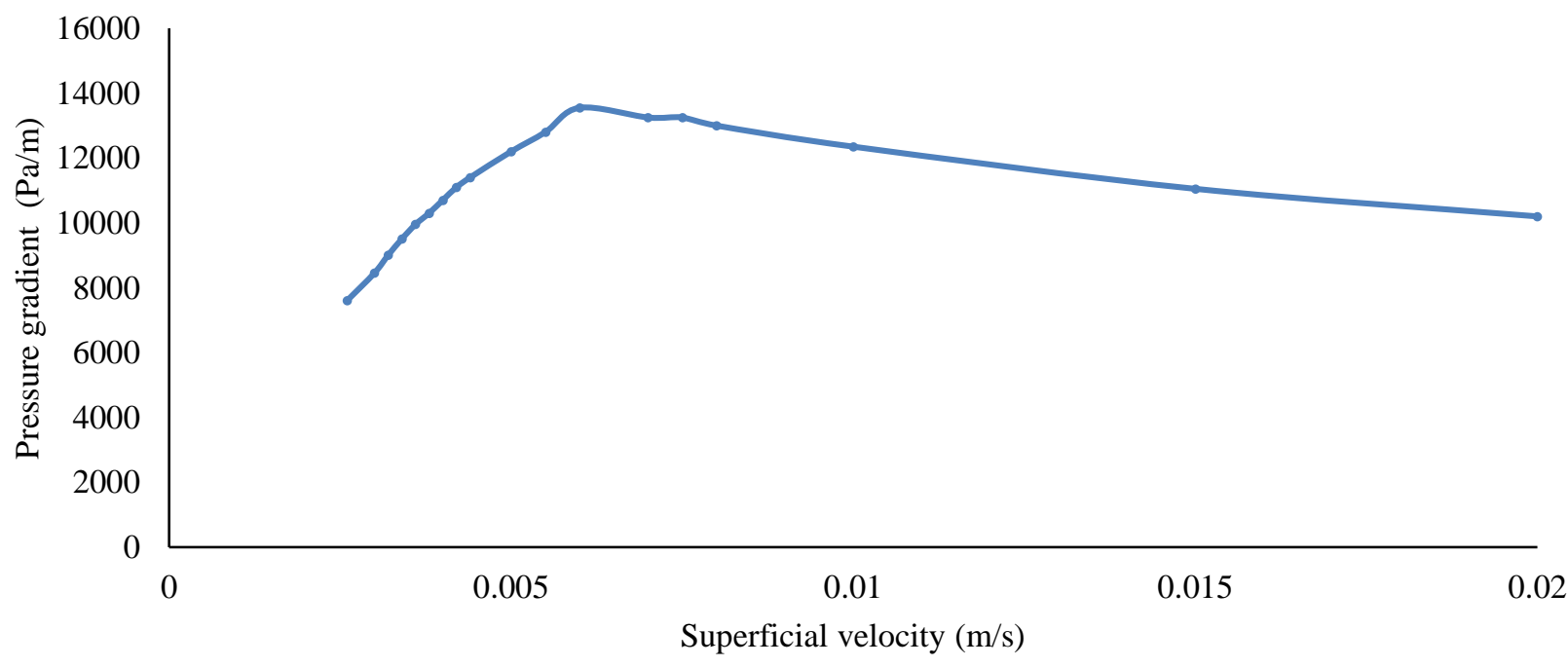

Figure 1. Group-A particles pressure-gradient variation with the inlet superficial velocity 


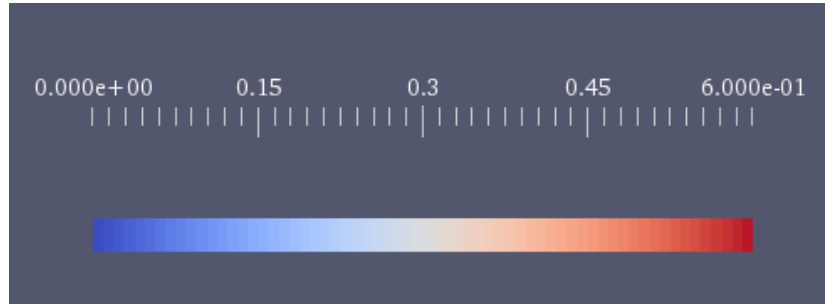

Figure 2. Color map for Figure 3, 5, 6, 7, 9, 11 and 12. Value zero (dark blue) represents the gas and value one (dark red) represents the solid.

$0.8 \mathrm{~m}$

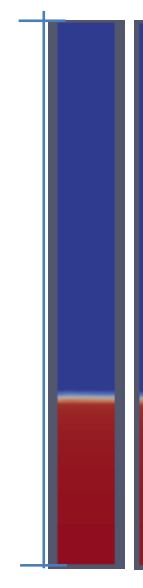

$0 \mathrm{~m}$

(a)

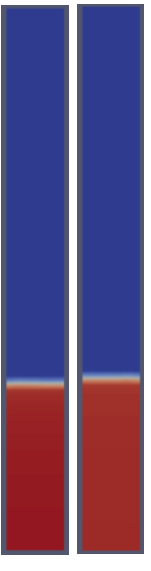

(b)

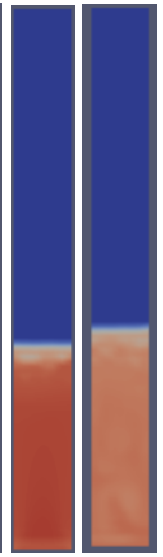

(d)

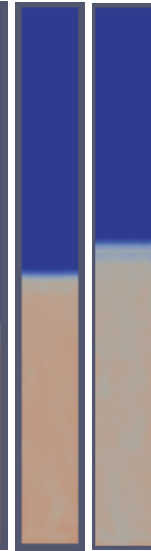

(f)

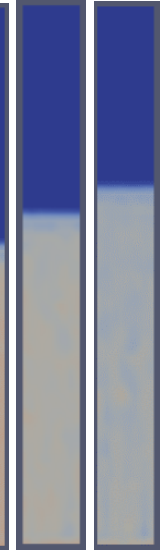

(g) (h) (i)

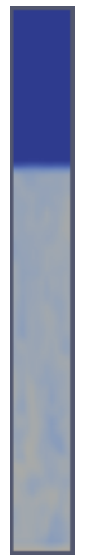

(j)
Figure 3. Solid volume fraction with different inlet superficial velocities, Geldart's classification Group-A, $\rho_{s}=2500 \mathrm{~kg} / \mathrm{m}^{3}, d_{p}=60 \mu \mathrm{m}$, the maximum column height is $0.8 \mathrm{~m}$; (a) $0.0026 \mathrm{~m} / \mathrm{s}$, (b) $0.0042 \mathrm{~m} / \mathrm{s}$, (c) 0.006 $\mathrm{m} / \mathrm{s}$, (d) $0.008 \mathrm{~m} / \mathrm{s}$, (e) $0.015 \mathrm{~m} / \mathrm{s}$, (f) $0.03 \mathrm{~m} / \mathrm{s}$, (g) $0.04 \mathrm{~m} / \mathrm{s}$, (h) $0.05 \mathrm{~m} / \mathrm{s}$, (i) $0.06 \mathrm{~m} / \mathrm{s}$, (j) $0.07 \mathrm{~m} / \mathrm{s}$

\subsubsection{Fluidization regimes}

Figure 5 shows a flow regime change with increase of the inlet superficial velocity. The packed bed can be considered as a normal packing (neither a dense packing nor a loose packing), because the minimum void fraction was 0.3564 and the sphericity was equal to one (Kunii \& Levenspiel, 1991). There is no bubble formation in Figure 5.a. This was due to the gas velocity lower than the minimum fluidization velocity. Approximate minimum fluidization is shown in Figure 5.b. There was no bubble formation at this stage. The size of bubbles is expanded from Figure 5.c to Figure 5.f. The minimum bubbling occurred at the inlet surficial velocity in in range $0.2 \mathrm{~m} / \mathrm{s}$ to $0.25 \mathrm{~m} / \mathrm{s}$. Figure 5.f shows a slug formation. A spouted bed behavior is shown in Figure 5.g. The spouted bed behavior was occurred, when the inlet superficial velocity was five times larger than the minimum fluidization velocity.

\subsubsection{Bubble formation and rise}

Figure 6 shows a bubble formation from the bottom of the bed and travel until the top of the bed. The bubble size increased gradually with time. The circular shape of the bubble changed into an elliptical shape at the end. This was due to the lower hydrostatic pressure applied to the bubble at the top of the bed. The average bubblerise velocity from the formation to the end was 0.426 $\mathrm{m} / \mathrm{s}$ (for the inlet superficial velocity $0.35 \mathrm{~m} / \mathrm{s}$ ), which was higher than the gas inlet velocity and higher than the minimum fluidization velocity. The diameter of the bubble varied from $0 \mathrm{~mm}$ to $42 \mathrm{~mm}$. Here, the average bubble size was $50 \%$ of the bed diameter. According to Equation-14, the calculated average bubble-rise velocity was $0.482 \mathrm{~m} / \mathrm{s}$, which was approximately equal to the simulation result. Most of the bubbles rise faster than the inlet superficial gas velocity (Geldart, 1972). The high bubble velocity is due to the low void fraction in the bed. These low voidages support to rise the bubbles faster than the inlet superficial velocity. Increase or decrease of bubble diameter depends on the balance of coalescence and splitting frequencies (Horio $\mathrm{M}$ \& Nonaka A, 1987). Group-B particle showed higher mixing than Group-A particles due to the more bubbles in the bed.

\subsubsection{Bubble splitting}

Figure 7 shows the bubble-splitting behavior. Here, dense phase particles collapsed onto the bubble and because of this, the bubble splits into two. Other bubbles and wall effects were also reasons to the bubble splitting.

\subsection{Group-C}

\subsubsection{Pressure gradient}

There are very few simulations related to Group-C particle fluidization found in literature. There is a real practical difficulty of the simulations, which takes higher simulation time due to very small velocities at minimum fluidization. In this study, a time step of $10^{-4} \mathrm{~s}$ was used for the simulations. Figure 8 shows pressure gradient variation with the inlet superficial velocity for Group-C particles. The minimum fluidization velocity was $3.75 \times 10^{-4} \mathrm{~m} / \mathrm{s}$.

\subsubsection{Flow regimes}

Group-C particles behaved as a fluid as shown in Figure 9 and it gave the higher flow behavior compared to the other groups. Even though the inlet superficial velocity was 25 times larger than the minimum fluidization velocity, there was no bubble formation. This was due to the high cohesive properties of Group-C particles. Due to strong extra inter-particle forces, bubble formation does not occur in beds with Group-C particles 


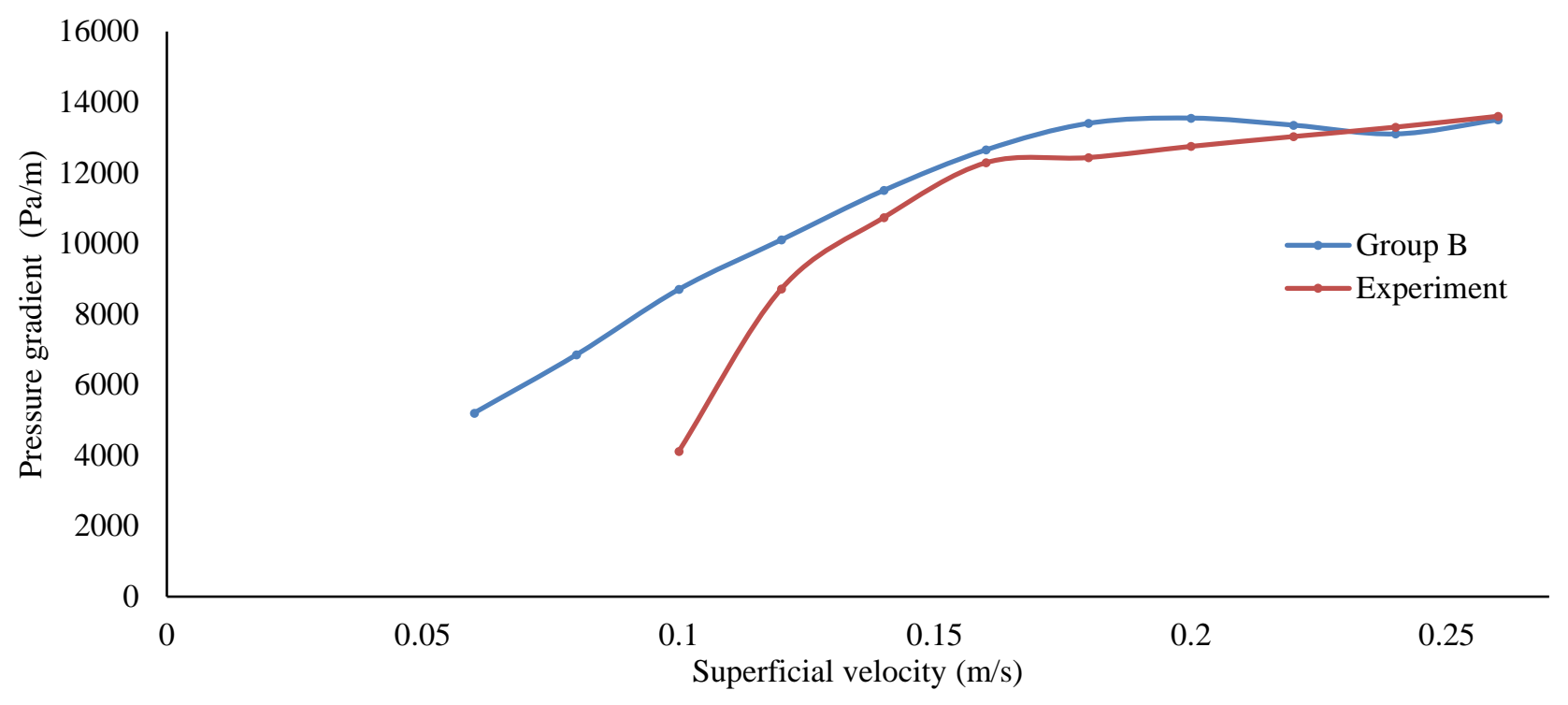

Figure 4. Group-B pressure-gradient variation with the inlet superficial velocity, the experimental result from (Thapa \& Halvorsen, 2013).

(Yao et al., 2002). However, the standard "twoPhaseEulerFoam" does not include the cohesive forces.

$$
1.4 \mathrm{~m}
$$

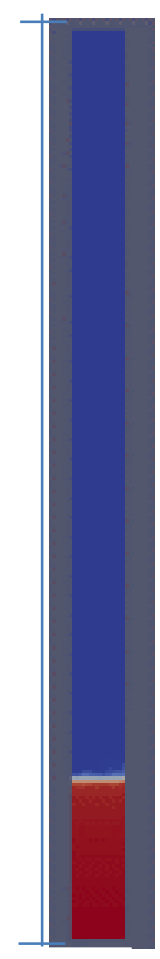

$0 \mathrm{~m}$
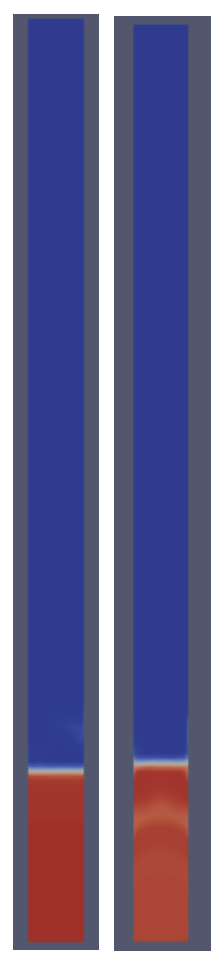

(b)

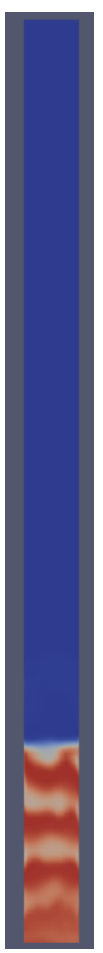

(c)

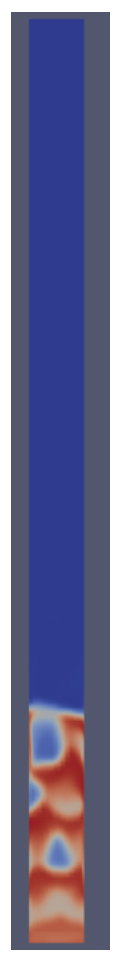

(d) (e)

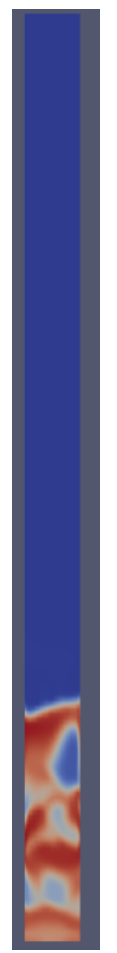

(f)

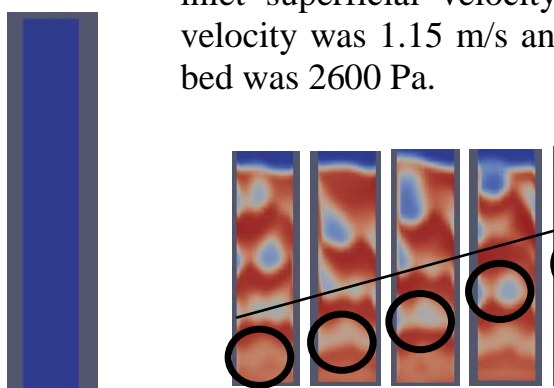

(a) bed was $2600 \mathrm{~Pa}$.

\subsection{Group-D}

\subsubsection{Pressure gradient}

Figure 10 shows the pressure gradient variation with the inlet superficial velocity. The minimum fluidization velocity was $1.15 \mathrm{~m} / \mathrm{s}$ and the pressure gradient in the

Figure 6. Bubble formation and rise vs. time, $d_{p}=$ $350 \mu \mathrm{m}, v=0.35 \mathrm{~m} / \mathrm{s}$; (a) $\mathrm{t}=2.5 \mathrm{~s}$, (b) $\mathrm{t}=3.0 \mathrm{~s}$, (c) $\mathrm{t}=3.5$ $\mathrm{s}$, (d) $\mathrm{t}=4.0 \mathrm{~s}$, (e) $\mathrm{t}=4.5 \mathrm{~s}$, (f) $\mathrm{t}=5.0 \mathrm{~s},(\mathrm{~g}) \mathrm{t}=5.5 \mathrm{~s}$, (h) $\mathrm{t}$ $=6.0 \mathrm{~s}$, (i) $\mathrm{t}=6.5 \mathrm{~s}$

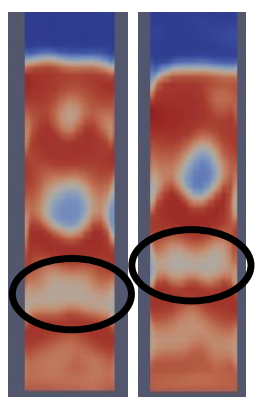

(a) (b)

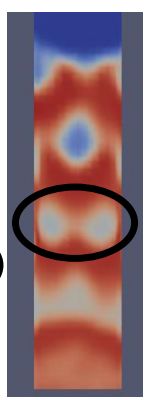

(c)

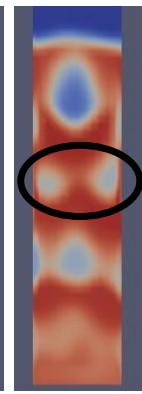

(d) superficial velocities, Geldart's classification, Group-B, $\rho_{s}=2500 \mathrm{~kg} / \mathrm{m}^{3}, d_{p}=350 \mu \mathrm{m}$, the maximum column height is $1.4 \mathrm{~m}$; (a) $0.05 \mathrm{~m} / \mathrm{s}$, (b) $0.2 \mathrm{~m} / \mathrm{s}$, (c) $0.25 \mathrm{~m} / \mathrm{s}$, (d) $0.3 \mathrm{~m} / \mathrm{s}$, (e) $0.4 \mathrm{~m} / \mathrm{s}$, (f) $0.45 \mathrm{~m} / \mathrm{s}$, (g) $1.0 \mathrm{~m} / \mathrm{s}$
Figure 7. Bubble splitting, $d_{p}=350 \mu \mathrm{m}, v=0.35 \mathrm{~m} / \mathrm{s}$; (a) $t=2.5 \mathrm{~s}$, (b) $t=3.0 \mathrm{~s}$, (c) $t=3.5 \mathrm{~s}$, (d) $t=4.0 \mathrm{~s}$ 


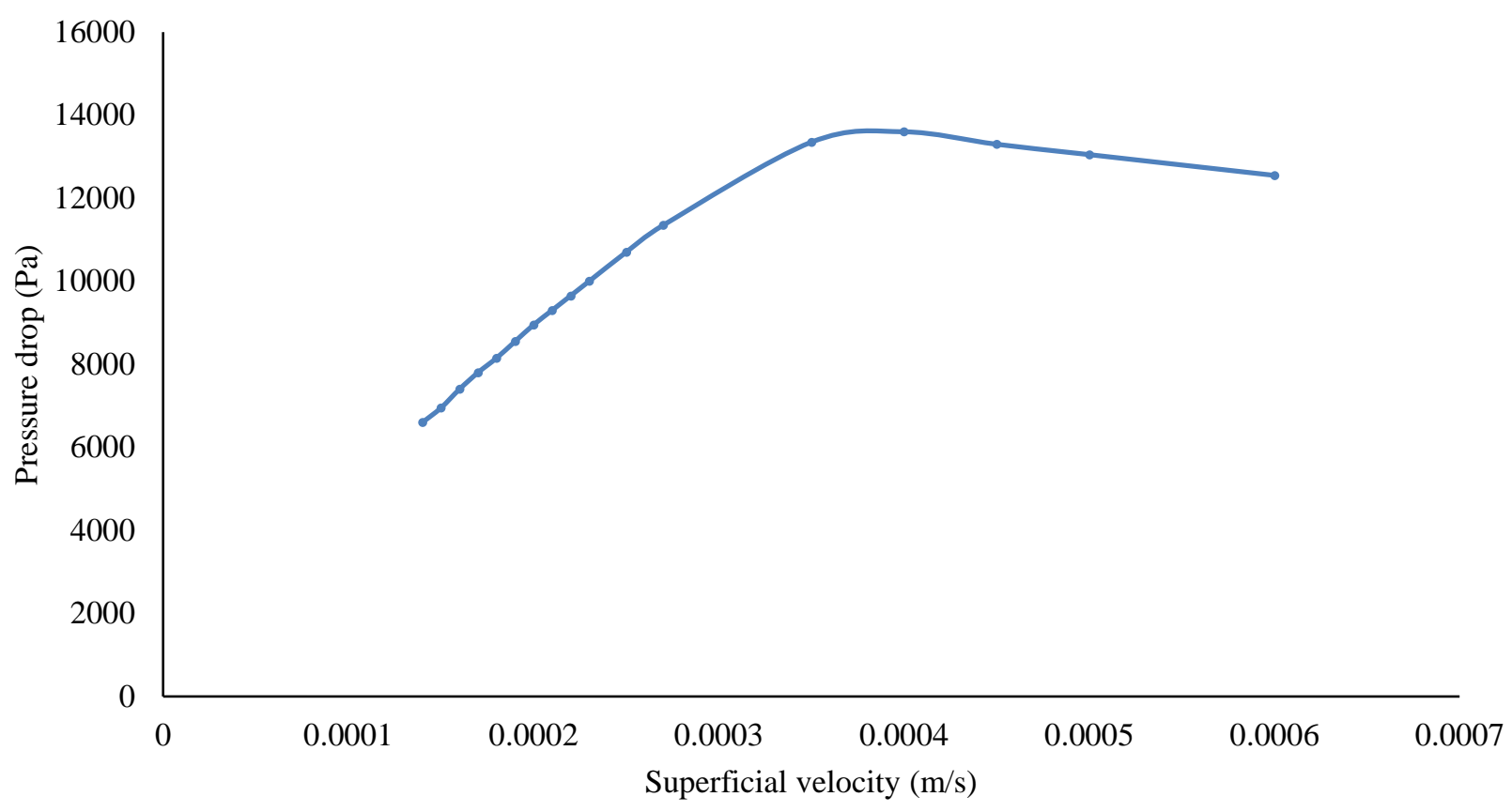

Figure 8. Group-C particles pressure-gradient variation with the inlet superficial velocity

$1.4 \mathrm{~m}$

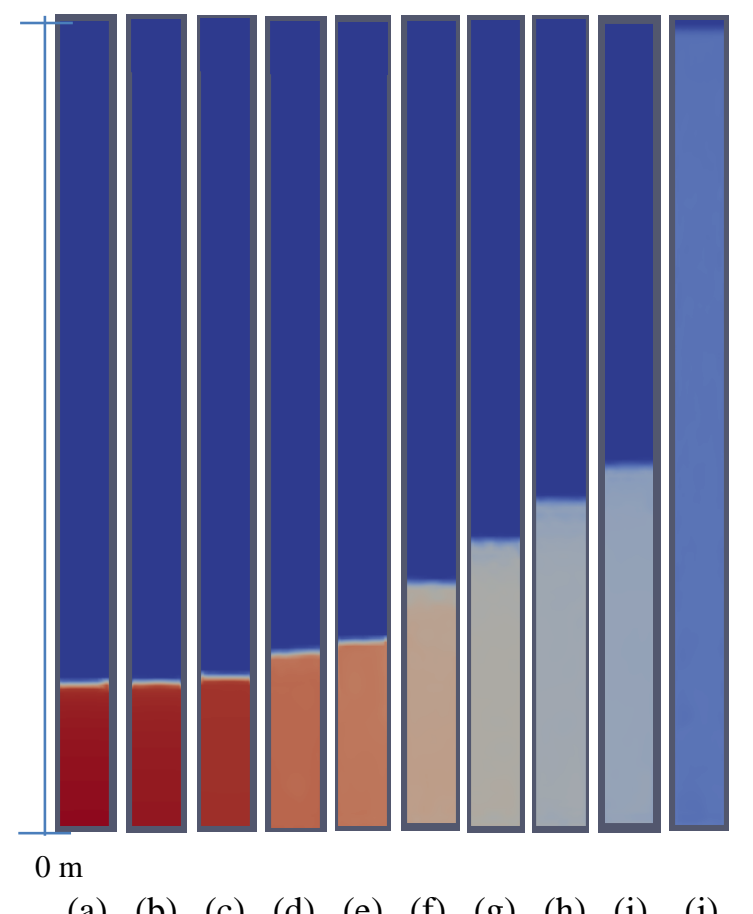

(a) (b) (c) (d) (e) (f) (g) (h) (i) (j)

Figure 9. Solid volume fraction, Geldart's classification, Group-C, $\rho_{s}=2500 \mathrm{~kg} / \mathrm{m}^{3}, d_{p}=15 \mu \mathrm{m}$, the maximum column height is $1.4 \mathrm{~m}$; (a) $0.00014 \mathrm{~m} / \mathrm{s}$, (b) $0.00027 \mathrm{~m} / \mathrm{s}$, (c) $0.0004 \mathrm{~m} / \mathrm{s}$, (d) $0.0008 \mathrm{~m} / \mathrm{s}$, (e) $0.001 \mathrm{~m} / \mathrm{s}$, (f) $0.002 \mathrm{~m} / \mathrm{s}$, (g) $0.003 \mathrm{~m} / \mathrm{s}$, (h) $0.004 \mathrm{~m} / \mathrm{s}$, (i) $0.005 \mathrm{~m} / \mathrm{s}$, (j) $0.01 \mathrm{~m} / \mathrm{s}$ after $380 \mathrm{~s}$

\subsubsection{Flow regimes}

Figure 11 shows solid volume fraction change with increase of the inlet superficial velocity. Flow behavior was similar with Group-B particles. However, bubbles were not stable as for Group-B and they were splitting faster. Back mixing was slower compared to Group-B particles (Geldart, 1972).

\subsubsection{Bubbles formation}

The shapes of the bubbles changed rapidly. The average size of the bubbles is larger than the average size of Group-B bubbles. The bubbles were very unstable at the top of the bed. There were large openings of bubbles at the top of the bed as shown in Figure 12. The average bubble size was $0.07 \mathrm{~m}$, which was approximately equal to the width of the column $\left(d_{t}=0.082 \mathrm{~m}\right)$. The calculated average bubble-rise-velocity was $1.04 \mathrm{~m} / \mathrm{s}$ from Equation-14. However, the simulated average bubble rise velocity was $0.4 \mathrm{~m} / \mathrm{s}$. Group-D bubbles rose at lower speed than the inlet superficial velocity. This is due to Group-D bubbles being comparatively larger and this creates higher voidages to rise the gas compared to the other groups. 


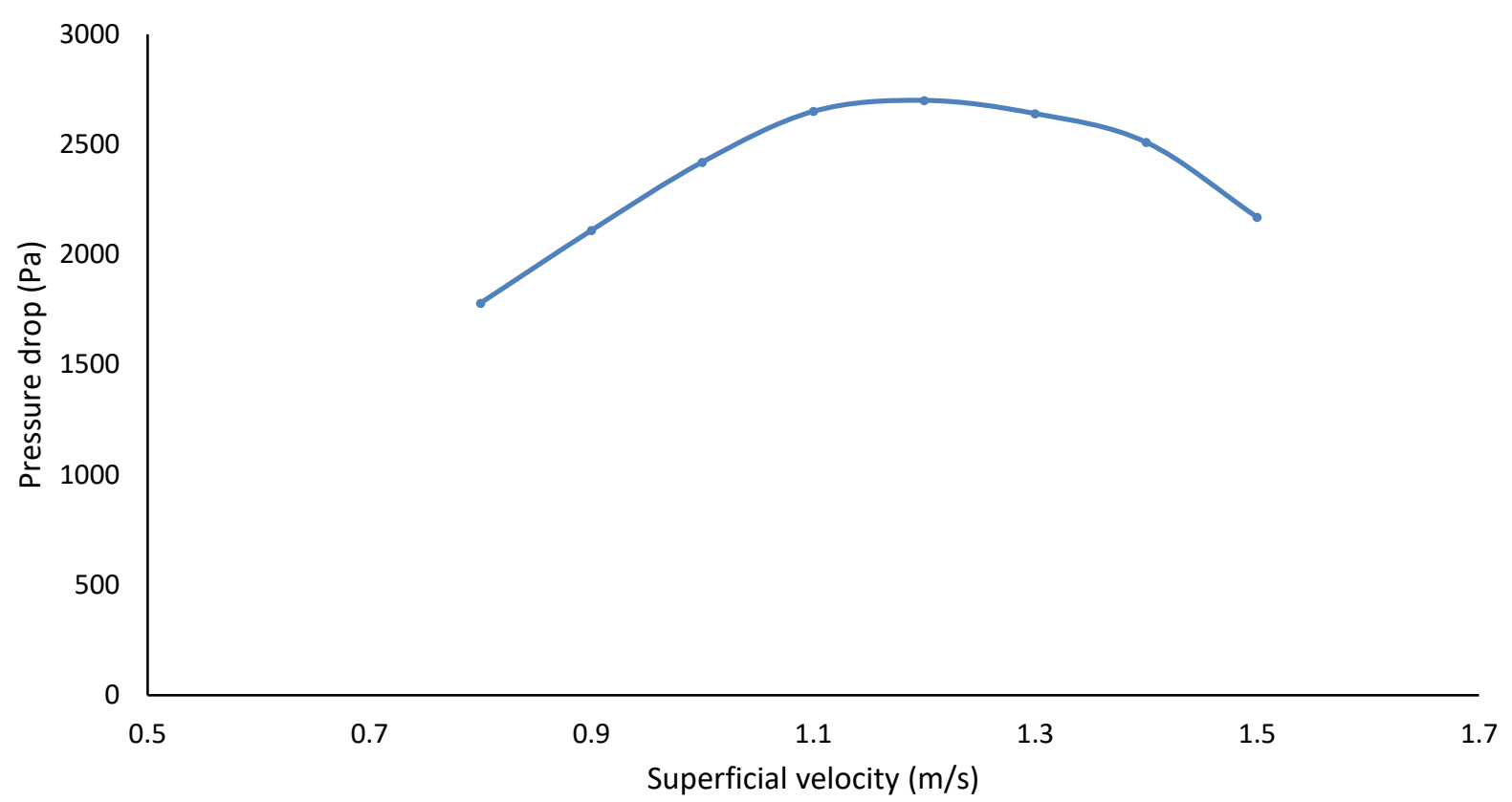

Figure 10. Group-D particle pressure-gradient variation with the inlet superficial velocity

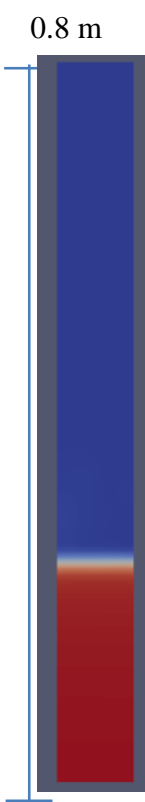

$0 \mathrm{~m}$

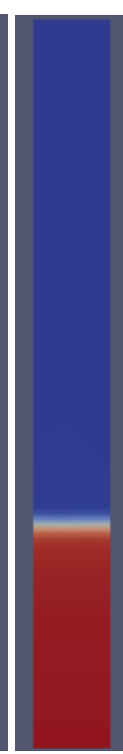

(b)

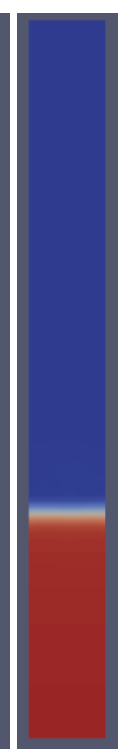

(c)

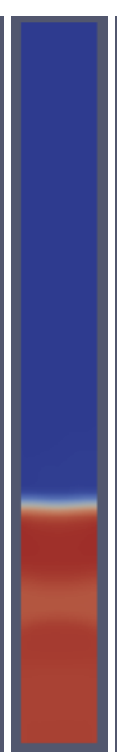

(d)

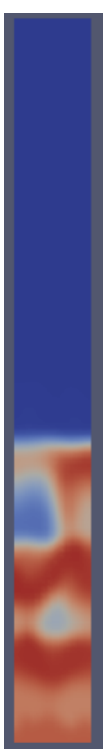

(e)

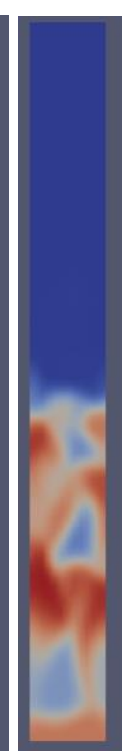

(f)

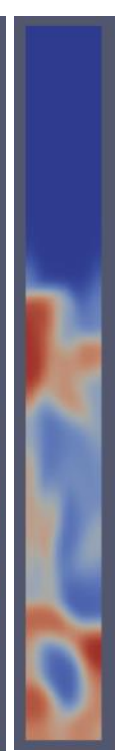

(g)

Figure 11. Solid volume fraction after $70 \mathrm{~s}$, Geldart's classification, Group-D, $\rho_{s}=2500 \mathrm{~kg} / \mathrm{m}^{3}, \quad d_{p}=$ $1500 \mu \mathrm{m}$, the maximum column height is $0.8 \mathrm{~m}$; (a) 0.8 $\mathrm{m} / \mathrm{s}$, (b) $0.9 \mathrm{~m} / \mathrm{s}$, (c) $1.1 \mathrm{~m} / \mathrm{s}$, (d) $1.3 \mathrm{~m} / \mathrm{s}$, (e) $1.5 \mathrm{~m} / \mathrm{s}$, (f) 2.0 $\mathrm{m} / \mathrm{s}$, (g) $2.5 \mathrm{~m} / \mathrm{s}$

\section{Comparison of Group-A, B, C, and D}

\subsection{Bed expansion}

Figure 13 shows bed expansion with the inlet superficial velocity for the all four particle groups. The bed

expansion factor was defined as $\frac{h}{h_{m f}}$. Here $h$ was the bed height and $h_{m f}$ was the bed height at the minimum fluidization. The expansions were considered until the bubble formation occurred. Group-C particles showed the highest bed expansion ratio, which was 1 to 2.5 times. Group-A particles showed a bed expansion 1 to 2.1 times. Group-B particles showed a bed expansion 1 to 1.2 times. Group-D particles gave lowest bed expansion that was 1 to 1.05 times. Group-C expanded with the smallest velocities and Group-D expanded with the largest velocities.

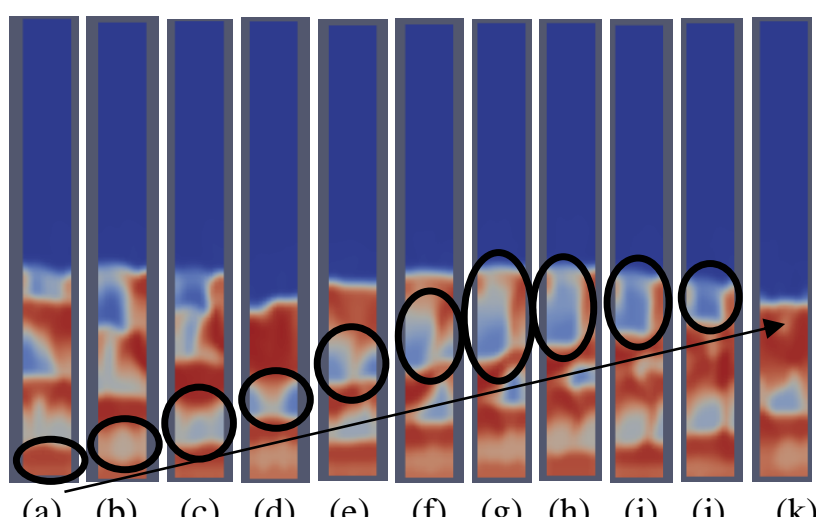

Figure 12. Bubble formation and rise of Group-D particles, $d_{p}=1500 \mu \mathrm{m}, v=1.6 \mathrm{~m} / \mathrm{s}$; (a) $\mathrm{t}=1.55 \mathrm{~s}$, (b) $\mathrm{t}$ $=1.72 \mathrm{~s}$, (c) $\mathrm{t}=1.80 \mathrm{~s}$, (d) $\mathrm{t}=1.91 \mathrm{~s}$, (e) $\mathrm{t}=2.05 \mathrm{~s}$, (f) $\mathrm{t}=$ $2.13 \mathrm{~s},(\mathrm{~g}) \mathrm{t}=2.18 \mathrm{~s}$, (h) $\mathrm{t}=2.23 \mathrm{~s}$, (i) $\mathrm{t}=2.28 \mathrm{~s},(\mathrm{j}) \mathrm{t}=2.32$ $\mathrm{s},(\mathrm{k}) \mathrm{t}=2.38 \mathrm{~s}$ 


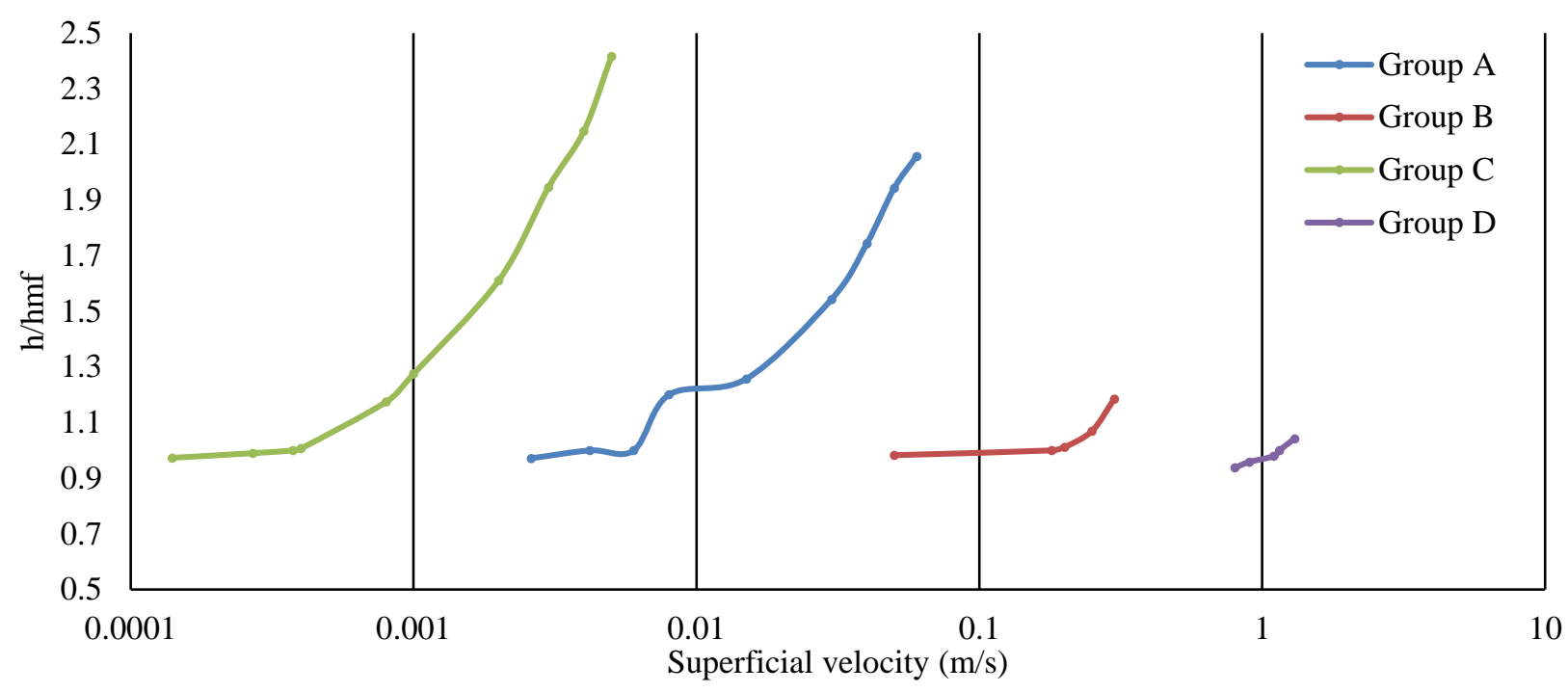

Figure 13. Bed expansion with the inlet superficial velocity for Group-A, B, C and D particles. X-axis is given in log

\subsection{Void fraction at the minimum fluidization}

The void fraction at the minimum fluidization is an important parameter for many calculations. Table .2 gives minimum fluidization velocity $\left(u_{m f}\right)$, bed height at the minimum fluidization $\left(h_{m f}\right)$ and void fraction at minimum fluidization $\left(\alpha_{m f}\right)$. The minimum allowable void fraction was defined as 0.3564 during the simulations. The void fraction at minimum fluidization was calculated as the average void fraction in a packed bed.

Table 2. Simulated results at minimum fluidization for all the four groups

\begin{tabular}{|l|l|l|l|l|}
\hline & Group-A & Group-B & Group-C & Group-D \\
\hline$d_{p}(\mu \mathrm{m})$ & 60 & 350 & 15 & 1500 \\
\hline$u_{m f}(\mathrm{~m} / \mathrm{s})$ & 0.006 & 0.19 & 0.000375 & 1.15 \\
\hline$h_{m f}(\mathrm{~mm})$ & 255 & 263 & 256 & 259 \\
\hline$\alpha_{m f}$ & 0.4427 & 0.4539 & 0.4467 & 0.4565 \\
\hline
\end{tabular}

\section{Conclusions}

Group-A and -C particles show bubble-less bed expansion. Group-C particles show the highest bed expansion ratio and Group-D particles show the lowest bed expansion ratio, respectively 2.5 times and 1.05 times, before bubble formation. A higher average bubble size occurs in Group-D particles than Group-B particles. Group-A and Group-C particles are less prone to mixing than Group-B and Group-D particles due to less bubble formation. Group-C particles show higher flow properties than the others. The minimum fluidization velocities become gradually smaller from Group-D, B, A to $\mathrm{C}$.

\section{Acknowledgement}

Economic support from The Research Council of Norway and Statoil ASA through project no. 255348/E30 "Sensors and models for improved kick/loss detection in drilling (Semi-kidd)" is gratefully acknowledged. The authors also gratefully acknowledge the resources for experiments and simulations provided by the University College of Southeast Norway.

\section{References}

Alavi S. and Caussat B. (2005). Experimental study on fluidization of micronic powders. Powder Technology, 157(1-3), 114-120 doi:http://dx.doi.org/10.1016/j.powtec.2005.05.017

Crowe C. T., Schwarzkopf J. D., Sommerfeld M. and Tsuji Y. (2011). Multiphase flows with droplets and particles: CRC press.

Geldart D. (1972). Types of Gas Fhidization Powder Technology,, 7(1973), 285-292.

Gidaspow D. (1994). Multiphase flow and fluidization : continuum and kinetic theory descriptions. Boston: Academic Press.

Horio M and Nonaka A. (1987). A generalized bubble diameter correlation for gas-sold fluidized beds AIChE Journal, 33(11), 1865-1872.

Karimipour S. and Pugsley T. (2010). Study of gas streaming in a deep fluidized bed containing Geldart's Group A particles. Chemical Engineering Science, 65(11), 35083517. doi:http://dx.doi.org/10.1016/j.ces.2010.02.045

Kunii D. and Levenspiel O. (1991). Fluidization engineering (2. ed.). Boston,Mass.: Butterworth-Heinemann.

Lu B., Wang W. and Li J. (2009). Searching for a meshindependent sub-grid model for CFD simulation of gassolid riser flows. Chemical Engineering Science, 
64(15),

doi:http://dx.doi.org/10.1016/j.ces.2009.04.024

Lu B., Wang W. and Li J. (2011). Eulerian simulation of gas-solid flows with particles of Geldart groups A, B and D using EMMS-based meso-scale model. Chemical Engineering Science, 66(20), 4624-4635. doi:http://dx.doi.org/10.1016/j.ces.2011.06.026

Motlagh A. H. A., Grace J. R., Salcudean M. and Hrenya C. M. (2014). New structure-based model for Eulerian simulation of hydrodynamics in gas-solid fluidized beds of Geldart group "A" particles. Chemical Engineering Science, 120, 22-36. doi:http://dx.doi.org/10.1016/j.ces.2014.08.042

Pandit J. K., Wang X. S. and Rhodes M. J. (2005). Study of Geldart's Group A behaviour using the discrete element method simulation. Powder Technology, 160(1), 7-14. doi:http://dx.doi.org/10.1016/j.powtec.2005.04.044

Pei P., Zhang K., Lu E. and Wen D. (2009). CFD simulation of bubbling and collapsing characteristics in a gas-solid fluidized bed. Petroleum Science, 6(1), 69-75. doi:10.1007/s12182-009-0013-0

Rusche H. (2002). Computational fluid dynamics of dispersed two-phase flows at high phase fractions. (Doctor of Philosophy), Imperial College London (University of London).

Thapa R. and Halvorsen B. (2013). Study of Flow Behavior in Bubbling Fluidized Bed Biomass Gasification Reactor Using CFD Simulation. Paper presented at the The 14th International Conference on Fluidization-From Fundamentals to Products. http://dc.engconfintl.org/fluidization_xiv/69

Wang J., van der Hoef M. A. and Kuipers J. A. M. (2009). Why the two-fluid model fails to predict the bed expansion characteristics of Geldart A particles in gas-fluidized beds: A tentative answer. Chemical Engineering Science, 64(3), 622-625. doi:http://dx.doi.org/10.1016/j.ces.2008.09.028

Wang J., van der Hoef M. A. and Kuipers J. A. M. (2011). The role of scale resolution versus inter-particle cohesive forces in two-fluid modeling of bubbling fluidization of Geldart A particles. Chemical Engineering Science, 66(18), 4229-4240. doi:http://dx.doi.org/10.1016/j.ces.2011.06.004

Wang X., Rahman F. and Rhodes M. (2007). Nanoparticle fluidization and Geldart's classification. Chemical Engineering Science, 62(13), 3455-3461. doi:http://dx.doi.org/10.1016/j.ces.2007.02.051

Yao W., Guangsheng G., Fei W. and Jun W. (2002). Fluidization and agglomerate structure of $\mathrm{SiO} 2$ nanoparticles. Powder Technology, 124(1-2), 152-159. doi:http://dx.doi.org/10.1016/S0032-5910(01)00491-0

Ye M., van der Hoef M. A. and Kuipers J. A. M. (2005). The effects of particle and gas properties on the fluidization of Geldart A particles. Chemical Engineering Science, 60(16), 4567-4580. doi:http://dx.doi.org/10.1016/j.ces.2005.03.017

Zhang K., Brandani S., Bi J. and Jiang J. (2008). CFD simulation of fluidization quality in the three-dimensional fluidized bed. Progress in Natural Science, 18(6), 729733. doi:http://dx.doi.org/10.1016/j.pnsc.2008.02.002 